\title{
Association of Hypertension with Body Mass Index
}

\author{
IMAM H ${ }^{1}$, ROY SK ${ }^{2}$, DAS PR ${ }^{3}$, BHUIYAN AR ${ }^{4}$, HOSSAIN MZ $^{5}$, KHAN MR $^{6}$
}

\begin{abstract}
:
Background: Body mass index (BMI) is positively associated with blood pressure (BP). Weight loss significantly reduces blood pressure (BP). The principal aim was to find out the association of Body Mass Index (BMI) with hypertension. Methods: This crosssectional study was conducted at outpatient department of Bangabandhu Sheikh Mujib Medical University (BSMMU). A total of 1128 hypertensive patients were included in this study by purposive sampling method. Staging of hypertension was done according to The JNC 7 Hypertension Guidelines. BMI was calculated by measuring weight in kilograms divided by height in meters squared. Results: This study demonstrated that majority (58.1\%) were within 40 to 60 years. $63.7 \%$ patients were male and $36.3 \%$ were female. Maximum observed systolic blood pressure was $170 \mathrm{~mm}$ of $\mathrm{Hg}$ and minimum $110 \mathrm{~mm}$ of $\mathrm{Hg}$. Maximum diastolic blood pressure was $120 \mathrm{~mm}$ of $\mathrm{Hg}$ and minimum 60 $\mathrm{mm}$ of $\mathrm{Hg}$. Out of 1128 hypertensive patients' $21 \%$ patients had normal BMI, $66.7 \%$ overweight, $8.8 \%$ obese and $3.5 \%$ patients were under weight. So hypertension was found more in overweight study subjects which was found statistically significant. Conclusion: The prevalence of hypertension is more in increased BMI.
\end{abstract}

Keywords: Hypertension, Body weight, BMI etc.

\section{Introduction:}

Body mass index (BMI) is positively associated with blood pressure (BP); this association has critical implications for countries like China, where hypertension is highly prevalent and obesity is increasing ${ }^{1}$. Weight loss significantly reduces blood pressure (BP), suggesting that $\mathrm{BMI}$ is not merely a marker of factors associated with high BP but is causally associated ${ }^{2-4}$. Hypertension has proven to be a silent killer contributing to many deaths and considerably increasing morbidity Worldwide ${ }^{5}$.

Hypertension is rapidly emerging as a major public health problem in developing countries ${ }^{6} .25 \%$ of world adult population is already hypertensive. Almost three quarters of the hypertensive population are in developing countries ${ }^{7}$. Nationwide survey on NCD conducted in Bangladesh in 2010 indicated that the prevalence of hypertension is $17.9 \%^{8}$. Twelve million people suffers from hypertension in Bangladesh ${ }^{9}$. So this association might help in the prevention of hypertension and thereby prevent target organ damage.

\section{Methods:}

This cross-sectional study was conducted at outpatient department of Bangabandhu Sheikh Mujib Medical University from January, 2017 to December, 2017. A total of 1128 patients were included in this study by purposive sampling method. All the patients were diagnosed cases of hypertension (BP >140/90 $\mathrm{mm}$ of $\mathrm{Hg}$ ). This study included adult patient aged $\geq 18$ years. Blood pressure was measured with a wellcalibrated sphygmomanometer.

Staging of hypertension was done according to The Seventh Report of the Joint National Committee on Prevention, detection, Evaluation and treatment of High Blood Pressure. Body mass index (BMI) of all hypertensive patients was then calculated as weight in kilograms divided by height in meters squared. In addition to physical measurements,

1. Dr. Hasan Imam, Assistant Professor, Dept. of Internal Medicine, BSMMU, Dhaka.

2. Dr. Sobroto kumar Roy, Junior consultant (Medicine), 250 bedded General Hospital, Gopalganj.

3. Dr. Pinaki Ranjan Das, Assistant professor, Dept. of Cardiology, NICVD, Dhaka.

4. Dr. Anisur Rahman Bhuiyan Assistant Professor, Dept. of Medicine, SSKMCH, Gopalganj

5. Dr. Md. Zakir Hossain, Professor, Dept. of Medicine, SZMCH, Bogura.

6. Dr. Md. Rafiquzzaman khan, Associate Professor, Dept. of Haematology, BSMMU, Dhaka. 
socio-demographic data and data on basic medical history were collected from standardized in-person interviews by trained medical staff.

\section{Results:}

This study intended to find the association between hypertension and BMI. The findings derived from data analyses were presented below.

In this study, out of 1128 hypertensive patients majority $655(58.1 \%)$ were between $40-60$ year of age and about $718(63.7 \%)$ were male and 410 $(36.3 \%)$ were female with significant association $(p<001)$. (Table-I).

Socio-demographic data demonstrated that educational status of the study subjects included majority $314(27.8 \%)$ were graduate with significant association $(p<0.001)$ and Occupation comprised majority were Service holder 548 (48.6\%) with significant association ( $p<0.001)$.Most $733(65 \%)$ patients were from rural areas and the rest (35\%) was from urban areas with significant association $(p<0.001)$. Majority of the study patients $851(75.4 \%)$ had no family history of hypertension with insignificant association ( $p=0.63)$. (Table-II).

Our analysis includes 1128 participants all were hypertensive. Among the study subjects, 715 participants $(66.7 \%)$ were overweight (BMI 25.0$29.9)$ with significant association $(p=0.002)$, and 128 participants $(10.3 \%)$ were obese (BMle"30) with significant association $(p<0.001)$, as defined by the World Health Organization international classification ${ }^{15,10}$. Majority $715(66.7 \%)$ patients were overweight. (Table-III).

Table-I

Distribution of age and sex of the study subjects $(n=1128)$

\begin{tabular}{lccc}
\hline Age (years) & \multicolumn{2}{c}{ Sex } & Total \\
\cline { 2 - 3 } & Male & Female & \\
\hline $18-40$ & $315(27.92 \%)$ & $140(12.41 \%)$ & $455(40.3 \%)$ \\
$40-60$ & $385(34.13 \%)$ & $270(23.93 \%)$ & $655(58.1 \%)$ \\
$>60$ & $18(1.6 \%)$ & $00(00 \%)$ & $18(1.6 \%)$ \\
\hline Total & $718(63.7 \%)$ & $410(36.3 \%)$ & $1128(100 \%)$ \\
\hline
\end{tabular}

Table-II

Socio-demographic characteristics of the study subjects $(n=1128)$

\begin{tabular}{llccc}
\hline Variables & & \multicolumn{2}{c}{ Sex } & Total \\
\cline { 3 - 4 } & & Male & Female & \\
\hline Educational & Primary & 207 & 63 & $270(23.9 \%)$ \\
Qualification & Secondary & 87 & 175 & $262(23.2 \%)$ \\
& Higher Secondary & 81 & 24 & $105(9.3 \%)$ \\
& Graduate & 286 & 28 & $314(27.8 \%)$ \\
Total & Postgraduate & 57 & 120 & $177(15.7 \%)$ \\
Occupation & Farmer & 718 & 410 & $1128(100 \%)$ \\
& Service & 138 & 00 & $138(12.2 \%)$ \\
& Businessman & 428 & 120 & $548(48.6 \%)$ \\
Total & Others & 152 & 00 & $152(13.5 \%)$ \\
Residence & Rural & 00 & 290 & $290(25.7 \%)$ \\
& Urban & 718 & 410 & $1128(100 \%)$ \\
Total & 195 & 200 & $395(35 \%)$ \\
Family history & Yes & 523 & 210 & $733(65 \%)$ \\
HTN & No & 718 & 410 & $1128(100 \%)$ \\
\hline Total & 718 & 100 & 53 & $153(13.56 \%)$ \\
\hline
\end{tabular}


Table-III

BMI of the study subjects $(n=1128)$

\begin{tabular}{llccc}
\hline Variables & & \multicolumn{2}{c}{ Sex } & Total \\
\cline { 3 - 4 } & & Male & Female & \\
\hline BMI & Normal & 163 & 73 & $236(20 \%)$ \\
& Overweight & 466 & 249 & $715(66.7 \%)$ \\
& Obese & 48 & 80 & $128(10.3 \%)$ \\
& Under weight & 41 & 08 & $49(3.5 \%)$ \\
\hline Total & & 718 & 410 & $1128(100 \%)$ \\
\hline
\end{tabular}

\section{Discussion:}

This study describes the association between BMI and BP which was conducted in tertiary care hospital of Bangladesh. In this study among 1128 hypertensive patients majority (58.1\%) were 40 to 60 years of age and $63.7 \%$ were male and $36.3 \%$ female with Male female ratio 1.75:1.

Hypertension is more common in men than in women of same age. Sex difference in the prevalence of hypertension may be mainly attributed to the differences in dietary habit, life style choice, salt intake, Physical activity level and some genetic polymorphism ${ }^{11}$.

Among 1128 hypertensive patients only $13.56 \%$ patients had positive family history and majority $(75.4 \%)$ patients had no family history of hypertension. Positive family history is associated with hypertension prevalence double that found in patients with negative history and is independent with weight. When over weight is also present, however hypertension prevalence is three to four times as high ${ }^{12}$.

BMI status of the study subjects found that majority $66.7 \%$ were overweight. The findings of this study is consistent with a study conducted in china, which also showed that the association of BMI with SBP and DBP was consistently positive across 86 subgroups defined by socio-demographic variables and was nearly linear, with little variation in its shape ${ }^{1}$.

\section{Conclusion:}

The prevalence of hypertension is more in increased BMI. The limitation of the present study is data were collected from single center. Further multi-center study was recommended to validate the finding of the present study.

\section{References:}

1. George C. Linderman, BS; Jiapeng Lu, PhD; Yuan Lu, ScD; Xin Sun, MS; Wei Xu, MS; et al. JAMA Network Open.2018; 1(4):e181271. doi:10.1001/jamanetworkopen.2018.71.

2. Rahmouni K, Correia ML, Haynes WG, Mark AL. Obesity-associated hypertension: new insights into mechanisms. Hypertension. 2005; 45(1):9-14. doi:10.1161/01.HYP. 0000 151325.83008.b4

3. Rahmouni K. Obesity-associated hypertension: recent progress in deciphering the pathogenesis. Hypertension.2014;64(2):215-221. doi:10.1161/HYPER TENSIONAHA.114. 00920

4. Sowers JR. Obesity as a cardiovascular risk factor.Am J Med. 2003; 115(suppl 8A):37S41S. doi:10.1016/j.amjmed.2003.08.012

5. Kotchen TA, Hypertensive Vascular Disease; In: Longo DL, Fauci SA, Kasper DL, Hauser SL, Jameson JL, Loscalzo J. Harrison's Principles of Internal Medicine ,18th edition. New York: McGrawHill publishers, 2012. Volll; 2042-59.

6. Hypertension Study Group. Prevalence, awareness, treatment and control of hypertension among the elderly in Bangladesh and India: A multicentre study. Bull World Health Organ. 2001; 79:490-500.

7. Kearny PM, Global burden of Hypertension: analysis of worldwide data. Lancet 2005; 365:217-23. 
8. Rahman M, Chowdhury MAJ etal.NCD Risk Factor Survey. BSM 2010; 1- 35.

9. Sultana M H. Non-adherence to drug treatment in patients of essential hypertension. BMRC Bull; 2009; 35: 76-78.

10. Consultation WHOE; WHO Expert Consultation. Appropriate body-mass index for Asian populations and itsimplications for policy and intervention strategies.Lancet.
2004; 363(9403):157-163. doi:10.1016/ S0140-6736(03)15268-3

11. Ruixin $Y$, Jinzhen $W$, Shangling $P$, Weixiong L, Dezhai Y, Yuming C. Sex differences in environmental and genetic factors for hypertension. The American journal of medicine 2008;121(9):811-819.

12. Stamler R, Stamler J, Reidlinger WF, Algera $\mathrm{G}$, Roberts RH. Family (Parentaral) history and prevalence of hypertension. JAMA 1979;241(1):43-46. 